\title{
A GENETIC AND EPIDEMIOLOGIC STUDY OF POLYDACTYLY IN HUMAN EMBRYOS IN JAPAN
}

\author{
Kohei ShIota ${ }^{1}$ and Ei MAtsunaga \\ Department of Human Genetics, National Institute of Genetics, \\ Mishima, Shizuoka, Japan
}

\begin{abstract}
Summary One hundred and twenty-nine embryos with polydactyly were found among 36,380 human conceptuses obtained through induced abortion during the period from 1962 to 1974, giving an overall incidence of $0.35 \%$; this must be taken as an underestimate because the denominator includes a large number of damaged embryos. A significant increase was noted in 1971 and 1972, and some exogenous factors, most probably ascertainment bias, were suspected to be responsible. About three quarters of the present cases had preaxial polydactyly in contrast to the predominance of postaxial type in Negro and Caucasian populations. The ratio unilateral to bilateral affection was approximately $2: 1$.

The mean maternal age did not differ significantly from that of the general embryonic population, indicating that chromosomal aberrations such as trisomies 13, 18 and 21 that are closely associated with maternal age may not constitute a major component as causes of Japanese polydactyly. Maternal pregnancy order had no effect upon the causation of this malformation. The case mothers were shown to have more frequent miscarriages than controls, suggesting the possible effect of some kind of maternal predisposition. No association was verified with paternal age, parental consanguinity nor with maternal medical history, including irregular menstrual cycle, and smoking and drinking habit. None of the cases was found to be familial. Argument was made that dominant inheritance is not a major cause and that complex genetic mechanisms or unknown exogenous factors may be responsible for the majority of the Japanese cases of polydactyly.
\end{abstract}

\section{INTRODUCTION}

Polydactyly is one of the common malformations in man, which is characterized by any duplication of one or more digits of the hand or foot. Numerous reported cases of polydactyly indicate that this anomaly has considerable variation in expressivity. According to the location of the extra digit, polydactyly is classified

Received February 8, 1978

1 Present address: Department of Anatomy, Faculty of Medicine, Kyoto University, Kyoto 606, Japan 
into two different categories, i.e., preaxial and postaxial (Warkany, 1971). Preaxial polydactyly is a condition represented by an extra thumb or large toe (partial or complete) involving a triphalangeal thumb. Index finger polydactyly which is encountered rather rarely is also included in this category. Postaxial polydactyly may have two clinical varieties. In type A, a well-formed articulated extra digit arises from the ulnar or fibular edge, while in type $\mathrm{B}$, the extra digit is vestigial and is frequently in the form of a skin tag, which is often referred to as pedunculated postminimus.

A dominant mutant gene has been suggested to be responsible for a certain proportion of postaxial polydactyly (Woolf and Woolf, 1970; McKusick, 1975). Familial occurrence was noted in $37-39 \%$ of the propositi with postaxial polydactyly in American whites (Woolf and Woolf, 1970) and in inhabitants of South American countries (Castilla et al., 1973). In those populations, familial tendencies were more remarkable for type $B$ than for type $A$ of postaxial polydactyly, suggesting that these two types are of separate entities. On the other hand, it is likely that preaxial polydactyly occurs by different mechanisms from those of postaxial type. In a genetic study of polydactyly in Utah (Woolf and Woolf, 1970), none of the 94 sibs of the 32 propositi with duplication of the first digit (thumb or large toe) was affected by this anomaly. Because of the low frequency of affected relatives, it was suggested that polygenes or exogenous factors are responsible for this type of polydactyly.

According to McKusick's catalog (1975), dominantly inherited polydactyly is recognized mainly as an isolated malformation. In addition to being an isolated malformation, polydactyly may occur as a part of several genetic syndromes some of which are autosomal recessive (Temtany and McKusick, 1969; Warkany, 1971; McKusick, 1975) or as a symptom of chromosomal aberrations such as trisomies 13, 18 and 21 (Pfeiffer and Santelmann, 1977). Sporadic cases of polydactyly are known to occur in otherwise normal persons. Although sporadic cases may not be rare, such cases usually remain unreported. Thus it is clear that polydactyly has considerable genetic heterogeneity.

Another striking feature of polydactyly is the racial difference in its incidence figures. This anomaly occurs about ten times more frequently in Negroes than in Caucasians (Frazier, 1960; Simpkiss and Lowe, 1961; Altemus and Ferguson, 1965; Woolf and Myrianthopoulos, 1973), and it is suggested that this malformation has a strong genetic component in Negro populations. In the Japanese, the incidence of polydactyly with and without associated anomalies has been reported as 0.9-1.2 per 1,000 newborns (Mitani, 1954; Ohkura, 1956; Neel, 1958). Neel (1958) compared the reported incidence figures of polydactyly in several racial groups and noted that the frequency at birth in Japanese is slightly higher than in Caucasians but much lower than in American Negroes. In a study of 44 Japanese infants with polydactyly, he found only one recurrence in 115 sibs of the propositi. Supported by a relative paucity of pedigrees that illustrate simple modes of inheritance for poly- 
dactyly in the Japanese literature, he concluded that the recurrence risk of this anomaly appeared to be lower in Japanese than in Caucasian populations. This suggests that most of the Japanese cases of polydactyly may occur by exogenous factors or by polygenes of low heritability. However, the relative frequencies of preaxial and postaxial types and the nature of exogenous factors in the etiology of Japanese polydactyly remain to be answered.

Although polydactyly is a rather common malformation, it is not always easy to collect a number of infant cases enough to make genetic and epidemiologic studies. On the other hand, Nishimura (1970) showed that the incidence of polydactyly is far higher in embryos-9.0 per 1,000 undamaged embryos-than in infants. This fact has made evident that a large proportion of the affected embryos are destined to be eliminated before birth. Thus the embryonic population could provide us with a unique opportunity for epidemiologic investigation on the etiology of polydactyly in man. As a result of expansion of the embryonic collection in Nishimura's laboratory, data are now available for 129 cases of polydactyly in all. The aim of this paper is to present some genetic and epidemiologic characteristics of these cases.

\section{MATERIALS AND METHODS}

The human embryos used in the present study were from the collection of human conceptuses in the Human Embryo Center for Teratological Studies, Faculty of Medicine, Kyoto University. This collection, which has been accomplished by Professor H. Nishimura and his associates, is composed of a large number of human conceptuses derived from artificial termination of pregnancy. The number of the specimens collected between January 1962 and December 1974 amounted to 36,380 . In the majority of the cases, pregnancy was terminated by cervical dilatation and curettage for "socio-economic" reasons under the Eugenic Protection Law. They occasionally contained the cases of threatened abortion as judged by the obstetricians. The term "threatened abortion" does not only mean a beginning or incomplete abortion; it is used if the obstetricians considered the probability of spontaneous abortion be more or less high depending upon the degree and duration of genital bleeding and/or other clinical symptoms. The collection also contains a relatively small number of the cases obtained by means of hysterectomy or salpingectomy with such indications as uterine myoma or ectopic pregnancy.

For each of the specimens, information concerning medical, reproductive and family history of the mother was taken by the obstetrician before or soon after operation, using a standard interview form consisting of ca. 20 items. Further details of the collection and the characteristics of the embryonic population have been described elsewhere by Nishimura et al. (1968) and Matsunaga and Shiota (1977).

Among the embryonic specimens collected during the period from 1962 to 
1974, polydactyly was diagnosed in 129 instances. Photographs of some of the cases are shown in a monograph by Nishimura and Okamoto (1976). Since various types of polydactyly (e.g., index finger polydactyly, or types A and B of postaxial polydactyly) cannot easily be distinguished in embryos, the present series were classified into two broad categories only; preaxial and postaxial.

For epidemiologic analysis, three groups of embryos were drawn as controls from the same collection: (1) The 3,411 undamaged embryos, which may be regarded as representatives of the whole set of the collection for the reasons given elsewhere (Matsunaga and Shiota, 1977). This control group will be referred to as the "general embryonic population." (2) One case of externally normal embryo, for each case of polydactyly, matched for maternal age and the time of onset of the last menstruation. These cases were used for analysis of paternal age effect. (3) One case of externally normal embryo, for each affected case, matched for parity (pregnancy order) and the time of onset of the last menstruation. This control group was used for analysis of several factors other than parental age and partiy.

Of the 129 polydactyly cases, data concerning clinical and family history of the mother were not available for eight embryos; six with preaxial polydactyly of the hand and two with postaxial polydactyly of the foot.

\section{RESULTS}

\section{Source of the specimens}

The source of the 121 polydactylous embryos and of the parity-matched controls is shown in Table 1. About one third of the malformed embryos were obtained through induced abortion performed in women having a sign of threatened abortion, while this was the case in about $15 \%$ of the normal controls. The result shown in Table 1 indicates that not a few of the conceptions with a polydactylous embryo tend to terminate spontaneously from an early stage of gestation. About $11 \%$ $(14 / 129)$ of the malformed embryos were found to be dead in utero as judged by postmortem maceration.

\section{Types of polydactyly}

Table 2 shows the distribution of the 129 embryos by the type and laterality of the defect. More than $80 \%$ of the cases had hand polydactyly. Of the cases with hand polydactyly, preaxial type was about 8 times more frequent than postaxial one, while in the foot, the latter type predominated over the former in inverse ratio. Among the cases with unilateral polydactyly, there was no significant preference of either right or left side.

In human characters with known etiological heterogeneity, such as retinoblastoma, bilateral affection may be regarded as a sign of greater contribution by genetic rather than by exogenous factors, while the reverse may be applied to unilateral affection. It is therefore interesting to see that, in our data, the relative 
Table 1. Source of the polydactylous embryos and of the parity-matched controls.

\begin{tabular}{|c|c|c|c|c|c|c|c|c|c|}
\hline \multirow{3}{*}{$\begin{array}{l}\text { Method of } \\
\text { acquisition }\end{array}$} & \multicolumn{7}{|c|}{ Polydactyly } & \multicolumn{2}{|c|}{ Control } \\
\hline & \multicolumn{2}{|c|}{ Hand } & \multicolumn{2}{|c|}{ Foot } & \multirow{2}{*}{$\begin{array}{l}\text { Hand } \\
\text { and } \\
\text { foot }\end{array}$} & \multicolumn{2}{|c|}{ Total } & \multirow[b]{2}{*}{ No. } & \multirow[b]{2}{*}{$\%$} \\
\hline & $\begin{array}{l}\text { Pre- } \\
\text { axial }\end{array}$ & $\begin{array}{l}\text { Post- } \\
\text { axial }\end{array}$ & $\begin{array}{l}\text { Pre- } \\
\text { axial }\end{array}$ & $\begin{array}{l}\text { Post- } \\
\text { axial }\end{array}$ & & No. & $\%$ & & \\
\hline $\begin{array}{l}\text { Induced abortion, } \\
\text { without a sign of } \\
\text { threatened abortion }\end{array}$ & 50 & 19 & & 14 & 2 & 76 & 62.8 & 90 & 74.4 \\
\hline $\begin{array}{l}\text { Induced abortion, } \\
\text { with a sign of } \\
\text { threatened abortion }\end{array}$ & 31 & 2 & 0 & 1 & 3 & 37 & $30.6^{*}$ & 18 & 14.9 \\
\hline Hysterectomy & $\mathbf{0}$ & 0 & 1 & 0 & 0 & 1 & 0.8 & 1 & 0.8 \\
\hline Ectopic pregnancy & 1 & 0 & 0 & 0 & 0 & 1 & 0.8 & 1 & 0.8 \\
\hline Unknown & 4 & 1 & 0 & 0 & 1 & 6 & 5.0 & 11 & 9.1 \\
\hline Total & 86 & 12 & 2 & 15 & 6 & 121 & 100.0 & 121 & 100.0 \\
\hline
\end{tabular}

*Significantly different from controls $(\mathrm{P}<0.01)$.

Table 2. Distribution of the 129 polydactylous embryos by the type of the defect.

\begin{tabular}{|c|c|c|c|}
\hline & Type & No. of cases & $\%$ \\
\hline \multirow{4}{*}{ Hand } & Preaxial 92 (Unilateral & 64 & 49.6 \\
\hline & $(71.3 \%) \quad$ Bilateral & 28 & 21.7 \\
\hline & Postaxial 12 (Unilateral & 4 & 3.1 \\
\hline & $(9.3 \%) \quad\{$ Bilateral & 8 & 6.2 \\
\hline \multirow{4}{*}{ Foot } & Preaxial 2 (Unilateral & 2 & 1.6 \\
\hline & $(1.6 \%) \quad$ Bilateral & 0 & 0.0 \\
\hline & Postaxial 17 Unilateral & 12 & 9.3 \\
\hline & $(13.2 \%) \quad$ Bilateral & 5 & 3.9 \\
\hline \multicolumn{2}{|c|}{ Hand and foot } & 6 & 4.7 \\
\hline \multicolumn{2}{|l|}{ Total } & 129 & 100.0 \\
\hline
\end{tabular}

proportion of the cases which involved bilateral hands or feet was larger in postaxial than in preaxial group. This finding is consistent with the results obtained by family studies that the recurrence among the relatives was more frequent for postaxial than for preaxial polydactyly (Woolf and Woolf, 1970). All of the six cases involving all four limbs had postaxial polydactyly in at least two limbs. It is further to be noted that $82(63.6 \%)$ of the 129 cases were of unilateral affection.

\section{Developmental stages and associated anomalies}

The earliest developmental stage of human embryos at which the formation of a supernumerary digit can be diagnosed is stage 16 for the hand and stage 17 for the foot. Thus the developmental stages of the malformed embryos at the time of interruption of the pregnancy ranged from 16 to 23 (Table 3). 
Table 3. Distribution of the polydactylous embryos by developmental stages.

\begin{tabular}{|c|c|c|c|c|c|c|c|}
\hline \multirow{2}{*}{ Carnegie stage } & \multicolumn{2}{|c|}{ Hand } & \multicolumn{2}{|c|}{ Foot } & \multirow{2}{*}{$\begin{array}{c}\text { Hand } \\
\text { and foot }\end{array}$} & \multicolumn{2}{|c|}{ Total } \\
\hline & Preaxial & Postaxial & Preaxial & Postaxial & & No. & $\%$ \\
\hline 16 & 19 & 1 & & & & 20 & 15.5 \\
\hline 17 & 23 & & & & & 23 & 17.8 \\
\hline 18 & 24 & & 1 & & 1 & 26 & 20.2 \\
\hline 19 & 17 & 1 & & 1 & & 19 & 14.7 \\
\hline 20 & 6 & 6 & 1 & 5 & 1 & 19 & 14.7 \\
\hline 21 & 1 & 1 & & 11 & 2 & 15 & 11.6 \\
\hline 22 & 1 & 2 & & & 2 & 5 & 3.9 \\
\hline 23 & 1 & 1 & & & & 2 & 1.6 \\
\hline Total & 92 & 12 & 2 & 17 & 6 & 129 & 100.0 \\
\hline
\end{tabular}

Table 4. Associated external anomalies in polydactylous embryos.

\begin{tabular}{|c|c|c|c|c|c|c|c|}
\hline \multirow{2}{*}{ Associated anomalies } & \multicolumn{2}{|c|}{ Hand } & \multicolumn{2}{|c|}{ Foot } & \multirow{2}{*}{$\begin{array}{l}\text { Hand } \\
\text { and } \\
\text { foot }\end{array}$} & \multicolumn{2}{|c|}{ Total } \\
\hline & Preaxial & Postaxial & Preaxial & Postaxial & & No. & $\%$ \\
\hline Holoprosencephaly & 20 & 2 & & & 2 & 24 & 18.6 \\
\hline Cleft lip & 4 & 2 & & 1 & 1 & 8 & 6.2 \\
\hline External ear anomalies & 1 & & & & 1 & 2 & 1.6 \\
\hline Other limb defects & 3 & 1 & & & & 4 & 3.1 \\
\hline Hydrops of trunk & 1 & & & & & 1 & 0.8 \\
\hline Caudal dysplasia & 1 & & & & & 1 & 0.8 \\
\hline $\begin{array}{l}\text { Total } \\
(\% \text { of the total cases) }\end{array}$ & $\begin{array}{l}26 \\
(28.3)\end{array}$ & $\begin{array}{c}3 \\
(25.0)\end{array}$ & $\begin{array}{l}0 \\
(0.0)\end{array}$ & $\begin{array}{c}1 \\
(12.5)\end{array}$ & $\begin{array}{c}2 \\
(33.3)\end{array}$ & 32 & 24.8 \\
\hline
\end{tabular}

About a quarter of the polydactylous embryos were associated with other external malformations (Table 4). The most frequently associated anomaly was holoprosencephaly (cyclopia-arhinencephaly series) which is found in high incidence in human embryos (Matsunaga and Shiota, 1977). Malformations of internal organs are not summarized here because most of the present cases were too young to detect internal malformations.

\section{Incidence and distribution in time}

As described above, 129 cases of polydactyly were found among the total of 36,380 conceptuses, the overall incidence being 3.5 per 1,000 conceptions. Admittedly, however, this figure is an underestimate because the polydactylous embryos which had been too much damaged or macerated did not come to our attention and because the collection contains an appreciable number (about 27\%) of the cases younger than stage 16. We may therefore regard the figure of 9.0 per 1,000 undamaged embryos given by Nishimura (1970) as a standard incidence of this anomaly in the embryonic population. 
Assuming that the proportion of damaged or macerated embryos in our sample was uniformly distributed throughout the time under study, we examined the variation in incidence of polydactyly by year and month. The annual incidence of this anomaly during the 13 years is shown in Table 5 . It can be noted that the incidence of the total polydactyly cases inclusive increased significantly in 1971 and 1972. When we examined the variation in annual incidence after dividing the cases according to the type and laterality of the anomaly, significant increase was noted in 1971 and 1972 not only for preaxial (unilateral and bilateral) or unilateral polydactyly but also for bilateral one (preaxial and postaxial). Postaxial polydactyly (unilateral and bilateral) increased significantly in 1971 but not in 1972. From these findings, it is evident that the cluster in 1971 and 1972 was not limited to the increase in the cases with preaxial or unilateral polydactyly for which the role of exogenous factors is thought much greater than for postaxial or bilateral one.

Table 6 shows the distribution of months by the number of affected embryos in a month from 1965 to 1974 , during which the number of the specimens per year was satisfactorily large. The mean number of cases occurred in a month was 0.99 , which was close to the variance of 1.05 . The distribution of months by the number of cases agrees well with the expectation from the Poisson model. This finding implies that polydactyly occurs randomly through time and that the number in one month does not influence the number in other months.

\section{Seasonal variation}

Table 7 represents the distribution of the months of conception for the cases for which the exact date of the last menstruation was known. The 'expected' values were calculated on the basis of the vital statistics data for all live-births in Japan for the year of 1968; it was assumed that the distribution of the months of conception did not differ according to whether the conception ended in induced abortion or live-birth. Although there exists some variation in monthly occurrence, the difference from expected was not significant and no apparent sign was evident pointing to a regular cyclic trend by seasonal changes.

\section{Parity effect, after exclusion of maternal age effect}

In Table 8, the distribution of parity (pregnancy order) of the case mothers is shown, compared with the expected one for the general embryonic population. The expected distribution of parity which was corrected for maternal age was computed based on the joint distribution of maternal age and parity for the 3,411 undamaged embryos. The details of the method of calculation was described elsewhere (Matsunaga and Shiota, 1977). The mean parity of the mothers did not differ significantly between the different types of polydactyly. Although the overall mean parity of the case mothers (3.48) was lower than expected (3.78), the difference did not reach the significance level $(\mathrm{t}=1.13, \mathrm{P}>0.2)$. In addition, the relative incidence showed no consistent pattern with increasing parity. Thus there seems 


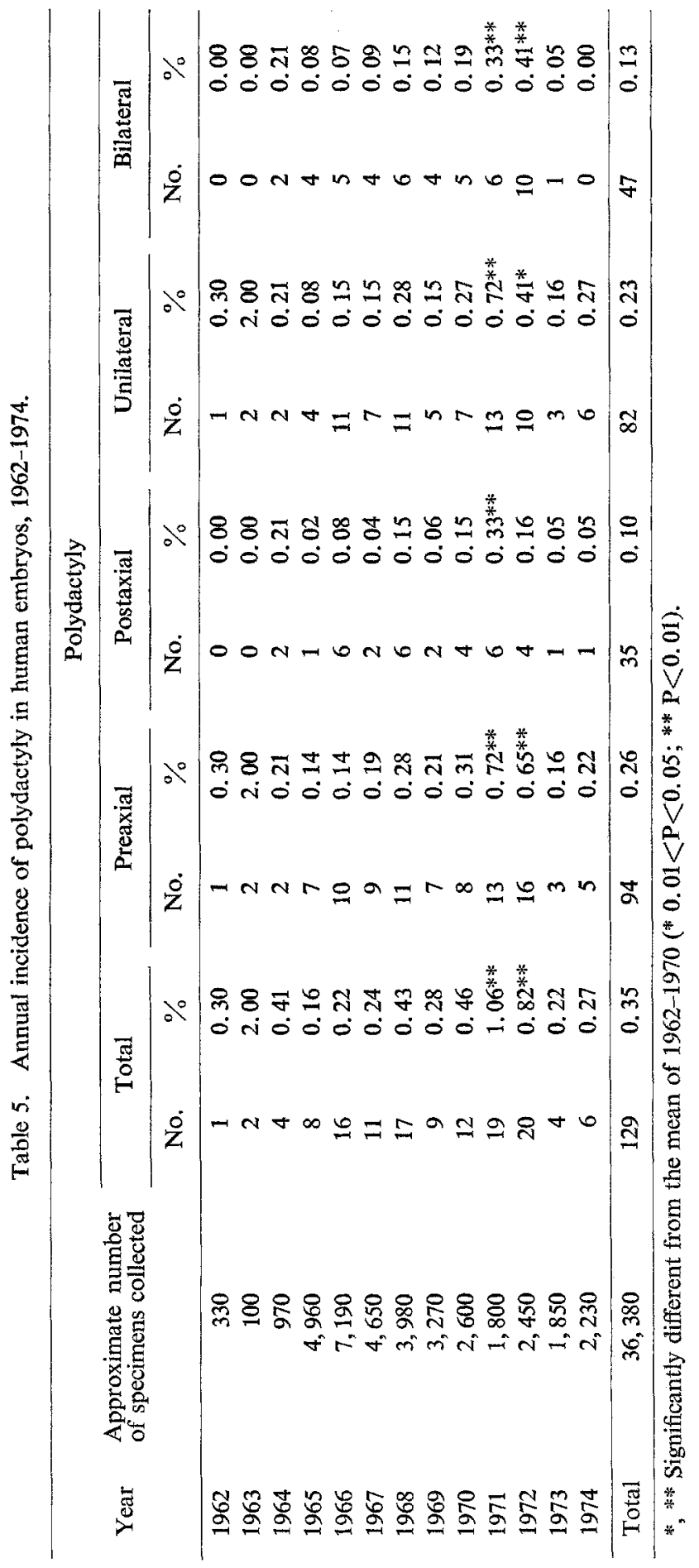


Table 6. Distribution of months by the number of polydactylous embryos in a month.

\begin{tabular}{cccc}
\hline \multirow{2}{*}{ No. of cases in a month } & \multicolumn{2}{c}{ No. of months, 1965-1974 } & \multirow{2}{*}{$\chi^{2}$} \\
\cline { 2 - 3 } & Observed & Expected* & \\
\hline 0 & 48 & 44.6 & 0.259 \\
1 & 38 & 44.1 & 0.844 \\
2 & 23 & 21.9 & 0.055 \\
3 & 9 & 7.2 \\
4 & 2 & 1.8 & \\
5 or more & 0 & 0.4 & 0.272 \\
\hline Total & 120 & 120.0 & 1.430 \\
Mean & 0.99 & & d.f. $=2$ \\
Variance & 1.05 & & P $>0.30$ \\
\hline
\end{tabular}

*Based on the Poisson model.

Table 7. Distribution of the polydactylous embryos by the month of conception.

\begin{tabular}{lcccr}
\hline $\begin{array}{l}\text { Month of } \\
\text { conception }\end{array}$ & $\begin{array}{c}\text { Observed no. } \\
\text { of cases }\end{array}$ & $\begin{array}{c}\% \text { distribution of total conceptions } \\
\text { in Japan* }\end{array}$ & $\begin{array}{c}\text { Expected no. } \\
\text { of cases }\end{array}$ & $\begin{array}{r}\text { Difference } \\
\text { Obs.-Exp. }\end{array}$ \\
\hline January & 12 & 8.06 & 10.2 & 1.8 \\
February & 8 & 7.91 & 10.0 & -2.0 \\
March & 8 & 8.63 & 10.9 & -2.9 \\
April & 13 & 8.80 & 11.1 & 1.9 \\
May & 16 & 8.03 & 10.1 & 5.9 \\
June & 10 & 8.46 & 10.7 & -0.7 \\
July & 6 & 8.65 & 10.9 & -4.9 \\
August & 4 & 8.25 & 10.4 & -6.4 \\
September & 12 & 7.77 & 9.8 & 2.2 \\
October & 13 & 8.71 & 11.0 & 2.0 \\
November & 15 & 8.56 & 10.8 & 4.2 \\
December & 9 & 8.17 & 10.3 & -1.3 \\
\hline Total & 126 & 100.0 & 126.2 & -0.2 \\
\hline
\end{tabular}

*Based on the vital statistics data for all live-births in 1968 (1,870,000 in number), the Ministry of Health and Welfare, Japan.

to be no effect of parity upon the causation of polydactyly.

Maternal age effect, after exclusion of parity effect

Table 9 shows the distribution of the case mothers by age, with the expected one which was constructed again from the data for the general embryonic population after correction of the variation in parity. The mean age of the case mothers was slightly higher than expected, but the difference was statistically not significant $(t=0.44, P>0.60)$. There was no significant difference in maternal age between the different types of the anomaly. 
Table 8. Distribution of parity in the study group and in the general embryonic population corrected for maternal age.

\begin{tabular}{|c|c|c|c|c|c|c|c|c|c|}
\hline \multirow{3}{*}{ Parity } & \multicolumn{6}{|c|}{ Polydactyly } & \multirow{3}{*}{$\begin{array}{l}\text { Expected } \\
\text { no. }\end{array}$} & \multirow{3}{*}{$\chi^{2}$} & \multirow{3}{*}{$\begin{array}{r}\text { Relative } \\
\text { incidence }\end{array}$} \\
\hline & \multicolumn{2}{|c|}{ Hand } & \multicolumn{2}{|c|}{ Foot } & \multirow{2}{*}{$\begin{array}{l}\text { Hand } \\
\text { and } \\
\text { foot }\end{array}$} & \multirow{2}{*}{ Total } & & & \\
\hline & Preaxial & Postaxial & Preaxial & Postaxial & & & & & \\
\hline 1 & 14 & 1 & 0 & 0 & 1 & 16 & 17.8 & 0.18 & 0.90 \\
\hline 2 & 22 & 4 & 0 & 4 & 1 & 31 & 19.7 & 6.48 & 1.57 \\
\hline 3 & 20 & 1 & 0 & 4 & 2 & 27 & 23.6 & 0.49 & 1.14 \\
\hline 4 & 11 & 2 & 0 & 2 & 0 & 15 & 20.0 & 1.25 & 0.75 \\
\hline 5 & 6 & 2 & 1 & 2 & 0 & 11 & 15.5 & 1.31 & 0.71 \\
\hline 6 & 5 & 0 & 0 & 2 & 2 & 9 & 10.4 & 0.19 & 0.87 \\
\hline 7 and more & 8 & 2 & 1 & 1 & 0 & 12 & 14.1 & 0.31 & 0.85 \\
\hline Total & 86 & 12 & 2 & 15 & 6 & 121 & 121.1 & 10.21 & 1.00 \\
\hline Mean & 3.30 & 3.75 & 6.50 & 3.87 & 3.50 & 3.48 & 3.78 & $\mathrm{P} \approx 0.10$ & \\
\hline Variance & 3.98 & 4.75 & 4. 50 & 3.27 & 4. 30 & 4.05 & 4.43 & & \\
\hline
\end{tabular}

Table 9. Distribution of maternal age in the study group and in the general embryonic population corrected for parity.

\begin{tabular}{|c|c|c|c|c|c|c|c|c|c|}
\hline \multirow{3}{*}{$\underset{\text { age }}{\text { Maternal }}$} & \multicolumn{6}{|c|}{ Polydactyly } & \multirow{3}{*}{$\begin{array}{c}\text { Expected } \\
\text { no. }\end{array}$} & \multirow{3}{*}{$\chi^{2}$} & \multirow{3}{*}{$\begin{array}{r}\text { Relative } \\
\text { incidence }\end{array}$} \\
\hline & \multicolumn{2}{|c|}{ Hand } & \multicolumn{2}{|c|}{ Foot } & \multirow{2}{*}{$\begin{array}{l}\text { Hand } \\
\text { and } \\
\text { foot }\end{array}$} & \multirow{2}{*}{ Total } & & & \\
\hline & Preaxial & Postaxial & Preaxial & Postaxial & & & & & \\
\hline-19 & 2 & 0 & 0 & 0 & 0 & 2 & 4.1 & \multirow{2}{*}{1.09} & \multirow{2}{*}{0.82} \\
\hline $20-24$ & 18 & 1 & 0 & 4 & 1 & 24 & 27.8 & & \\
\hline $25-29$ & 27 & 4 & 1 & 3 & 1 & 36 & 33.6 & 0.17 & 1.07 \\
\hline $30-34$ & 22 & 3 & 1 & 5 & 2 & 33 & 28.1 & 0.85 & 1.17 \\
\hline $35-39$ & 12 & 4 & 0 & 3 & 1 & 20 & 20.6 & 0.02 & 0.97 \\
\hline $40-44$ & 5 & 0 & 0 & 0 & 1 & 6 & 6.4 & \multirow{2}{*}{0.12} & \multirow{2}{*}{0.94} \\
\hline $45-$ & 0 & 0 & 0 & 0 & 0 & 0 & $0.5\}$ & & \\
\hline Total & 86 & 12 & 2 & 15 & 6 & 121 & 121.1 & 2.25 & 1.00 \\
\hline Mean & 29.56 & 31.08 & 31.00 & 29.21 & 32.56 & 30.10 & 29.75 & \multirow{2}{*}{$P>0.50$} & \\
\hline Variance & 35.57 & 25.17 & 12.50 & 36.34 & 50.00 & 34.62 & 40.75 & & \\
\hline
\end{tabular}

In our previous report (Matsunaga and Shiota, 1977), a complicated relationship between maternal age and parity was observed for holoprosencephalic embryos, and it was suggested that some of the mothers with low parity had underestimated the number of the previous pregnancies. Therefore, we compared again the maternal age of the present cases with the expected value after dividing the mothers into two groups, i.e., those with low (1 and 2 ) and high ( 3 and more) parity. In neither group, however, the mean age of the case mothers differed significantly from expected (observed vs. expected was 25.69 vs. 25.75 for the low parity group and 32.91 
Table 10. Maternal age distribution for polydactylous embryos, with and without associated anomalies.

\begin{tabular}{cccccc}
\hline & \multicolumn{5}{c}{ Polydactyly } \\
\cline { 2 - 3 } Maternal age & \multicolumn{2}{c}{ With other anomalies } & & \multicolumn{2}{c}{ Without other anomalies } \\
\cline { 2 - 3 } \cline { 5 - 6 } & \multicolumn{1}{c}{ No. } & $\%$ & & No. & $\%$ \\
\hline-19 & 0 & 0.0 & & 2 & 2.2 \\
$20-24$ & 3 & 9.4 & & 21 & 23.6 \\
$25-29$ & 14 & 43.8 & & 22 & 24.7 \\
$30-34$ & 8 & 25.0 & & 25 & 28.1 \\
$35-39$ & 6 & 18.8 & & 14 & 15.7 \\
$40-44$ & 1 & 3.1 & & 5 & 5.6 \\
\hline Total & 32 & 100.0 & & 89 & 100.0 \\
Mean & 30.63 & & & 29.92 & \\
Variance & 25.40 & & 38.13 & \\
\hline
\end{tabular}

vs. 32.30 for the high parity group).

It is well known that polydactyly is occasionally found in patients with trisomy 13 for which the risk increases with advancing maternal age (Smith, 1970). Since trisomy 13 syndrome is a complex of various defects, it seemed of some interest to examine whether there was any difference in maternal age between the cases with and without associated malformations. Although the mean of the former group (30.6) was slightly higher than that of the latter (29.9), there was no significant difference in the mean $(t=0.58, P>0.50)$ nor in the distribution $\left(\chi^{2}=0.11\right.$, d.f. $=2, P>$ 0.90 ) of maternal age between the two groups (Table 10).

\section{Paternal age effect, after exclusion of maternal age effect}

Information on paternal age was available for 93 cases. As shown in Table 11 , there was no difference in the mean nor in the distribution of paternal age between the cases and normal controls matched for maternal age. This result indicates that paternal age has no effect upon the production of polydactyly.

\section{Maternal history of miscarriages}

Among the 121 case mothers whose parity was known, 105 mothers were multiparous (Table 7). For these mothers and the control mothers matched for parity, the distribution of the number of previous miscarriages (spontaneous abortions and stillbirths) is shown in Table 12 . The proportion of the mothers having experienced at least one pregnancy wastage prior to the index pregnancy was $23.8 \%$ in the study group, whereas it was $15.2 \%$ in the control group, though the difference was not significant $\left(\chi^{2}=2.45,0.10<\mathrm{P}<0.20\right)$. It seems worthy of note that the mean number of miscarriages for the case mothers $(0.34)$ was greater than that for the controls $(0.23)$, though the difference again did not reach the significance level 
Table 11. Paternal age distribution for polydactyls and controls, matched for maternal age.

\begin{tabular}{|c|c|c|c|c|c|c|c|c|c|c|}
\hline \multirow{3}{*}{$\begin{array}{l}\text { Paternal } \\
\text { age }\end{array}$} & \multicolumn{7}{|c|}{ Polydactyly } & \multicolumn{2}{|c|}{ Control } & \multirow{3}{*}{$\begin{array}{l}\text { - Relative } \\
\text { incidence }\end{array}$} \\
\hline & \multicolumn{2}{|c|}{ Hand } & \multicolumn{2}{|c|}{ Foot } & \multirow{2}{*}{$\begin{array}{l}\text { Hand } \\
\text { and } \\
\text { foot }\end{array}$} & \multicolumn{2}{|c|}{ Total } & \multirow[b]{2}{*}{ No. } & \multirow[b]{2}{*}{$\%$} & \\
\hline & $\begin{array}{l}\text { Pre- } \\
\text { axial }\end{array}$ & $\begin{array}{l}\text { Post- } \\
\text { axial }\end{array}$ & $\begin{array}{l}\text { Pre- } \\
\text { axial }\end{array}$ & $\begin{array}{l}\text { Post- } \\
\text { axial }\end{array}$ & & No. & $\%$ & & & \\
\hline $20-24$ & 8 & 0 & 0 & 0 & 1 & 9 & 9.7 & 10 & 10.8 & 0.90 \\
\hline $25-29$ & 15 & 3 & 0 & 2 & 0 & 20 & 21.5 & 19 & 20.4 & 1.05 \\
\hline $30-34$ & 17 & 5 & 1 & 5 & 1 & 29 & 31.2 & 24 & 25.8 & 1.21 \\
\hline $35-39$ & 10 & 1 & 1 & 3 & 1 & 16 & 17.2 & 22 & 23.7 & 0.73 \\
\hline $40-44$ & 12 & 0 & 0 & 1 & 2 & 15 & 16.1 & 12 & 12.9 & 100 \\
\hline $45-$ & 3 & 0 & 0 & 0 & 1 & 4 & 4.3 & 6 & 6.5 & 1.06 \\
\hline Total & 65 & 9 & 2 & 11 & 6 & 93 & 100.0 & 93 & 100.0 & 1.00 \\
\hline Mean & 33.4 & 31.4 & 35.0 & 33.9 & 37.5 & 33.6 & & 33.8 & & \\
\hline Variance & 50.7 & 11.1 & 12.5 & 20.5 & 80.0 & 44.5 & & 47.9 & & \\
\hline
\end{tabular}

Table 12. History of previous miscarriages of the multiparous mothers in the study group and in the controls (parity-matched).

\begin{tabular}{cccccc}
\hline \multirow{2}{*}{ No. of previous miscarriages } & \multicolumn{2}{c}{ Mothers of polydactyls } & & \multicolumn{2}{c}{ Controls } \\
\cline { 2 - 3 } \cline { 5 - 6 } \cline { 5 - 6 } & No. & $\%$ & & No. & $\%$ \\
\hline 0 & 80 & 76.2 & & 89 & 84.8 \\
1 & 17 & 16.2 & & 12 & 11.4 \\
2 & 5 & 4.8 & & 1 & 1.0 \\
3 & 3 & 2.9 & & 2 & 1.9 \\
4 & 0 & 0.0 & & 1 & 1.0 \\
\hline Total & 105 & 100.0 & & 105 & 100.0 \\
Mean & 0.34 & & & 0.23 & \\
Variance & 0.504 & & 0.435 & \\
\hline
\end{tabular}

$(t=1.27, P>0.20)$. Although neither the mean nor the distribution differed significantly, it seems probable that the case mothers are somewhat more likely to have miscarriages in other pregnancies than the mothers of the normal embryos.

Menstrual cycle

In women having irregular menstrual cycle, the risk of delayed ovulation and delayed fertilization would be higher. As shown in Table 13, however, no difference was noted in the frequency of irregular menstrual cycle between the mothers of the cases and of the parity-matched controls, indicating that irregular menstruation does not increase the risk of polydactyly.

Maternal ill health during pregnancy

The frequency of the mothers who had had an illness during the index pregnancy 
Table 13. Regularity of menstrual cycles in the mothers of the study group and of the control group (parity-matched).

\begin{tabular}{lrrrrrr}
\hline \multirow{2}{*}{ Menstrual cycles } & \multicolumn{2}{c}{ Mothers of polydactyls } & & \multicolumn{2}{c}{ Controls } \\
\cline { 2 - 3 } \cline { 6 - 7 } & No. & $\%$ & & No. & $\%$ \\
\hline Regular & 106 & 87.6 & & 105 & 86.8 \\
Irregular & 15 & 12.4 & & 16 & 13.2 \\
\hline Total & 121 & 100.0 & & 121 & 100.0 \\
\hline
\end{tabular}

Table 14. Maternal medical history during pregnancy in the study group and in the control group (parity-matched).

\begin{tabular}{lccrrr}
\hline \multirow{2}{*}{ Disease } & \multicolumn{2}{c}{ Mothers of polydactyls } & & \multicolumn{2}{c}{ Controls } \\
\cline { 2 - 3 } \cline { 5 - 6 } & No. & $\%$ & & No. & $\%$ \\
\hline Influenza or fever & 6 & 5.0 & & 10 & 8.3 \\
Rubella & 0 & 0.0 & & 1 & 0.8 \\
Pulmonary tuberculosis & 2 & 1.7 & & 1 & 0.8 \\
Goiter or thyroiditis & 1 & 0.8 & & 1 & 0.8 \\
Anemia & 1 & 0.8 & & 3 & 2.5 \\
Cardiovascular disease & 2 & 1.7 & & 1 & 0.8 \\
Digestive disease & 2 & 1.7 & & 2 & 1.7 \\
Nephritis & 0 & 0.0 & & 1 & 0.8 \\
Ureter stone & 0 & 0.0 & & 1 & 0.8 \\
Myoma uteri & 1 & 0.8 & & 1 & 0.8 \\
Vaginal mycosis & 1 & 0.8 & & 1 & 0.8 \\
Hyperemesis & 3 & 2.5 & & 1 & 0.8 \\
Epilepsy & 1 & 0.8 & & 0 & 0.0 \\
Psychosomatic disease & 0 & 0.0 & & 1 & 0.8 \\
\hline Total cases & 18 & 14.9 & 22 & 18.2 \\
\hline
\end{tabular}

No. of cases examined $=121$ in each group.

did not differ significantly from that of the control mothers (Table 14). Association was not verified between polydactyly and any specific illness.

About $36 \%$ of the case mothers had genital bleeding during the terminated pregnancy (Table 15). Occurrence of threatened abortion was significantly more frequent among the case mothers than among the controls. Of the 35 polydactyly cases accompanied by a symptom of threatened abortion, 20 embryos were associated with other developmental defects such as holoprosencephaly. If we excluded these 20 cases, the difference in the frequency of threatened abortion between the study group and the controls became not significant. Thus the increase in genital bleeding and threatened abortion of the case mothers is mainly due to the associated serious malformations of the embryo, and not to polydactyly as an isolated malformation. 
Table 15. Maternal genital bleeding during the terminated pregnancy in the study group and in the control group (parity-matched).

\begin{tabular}{ccccrc}
\hline \multirow{2}{*}{ Genital bleeding } & \multicolumn{2}{c}{ Mothers of polydactyls } & & \multicolumn{2}{c}{ Controls } \\
\cline { 2 - 3 } \cline { 5 - 6 } & No. & $\%$ & & No. & $\%$ \\
\hline$(++)^{*}$ & 35 & $28.1^{* *}$ & & 18 & 14.9 \\
$(+)$ & 9 & 7.4 & & 8 & 6.6 \\
$(-)$ & 77 & 64.5 & & 95 & 78.5 \\
\hline Total & 121 & 100.0 & & 121 & 100.0 \\
\hline
\end{tabular}

*Accompanied by symptoms of threatened abortion.

**Significantly different from controls $\left(\gamma^{2}=7.41\right.$, d.f. $\left.=1, P<0.01\right)$.

Table 16. Maternal drug consumption and irradiation during pregnancy in the study group and in the control group (parity-matched).

\begin{tabular}{lrrrrr} 
& \multicolumn{2}{c}{ Mothers of polydactyls } & & \multicolumn{2}{c}{ Controls } \\
\cline { 6 - 7 } \cline { 5 - 6 } \cline { 5 - 6 } & No. & $\%$ & & No. & $\%$ \\
\hline Progestagens & 20 & 16.5 & & 13 & 10.7 \\
Estrogens & 6 & 5.0 & & 8 & 6.6 \\
Analgesics & 1 & 0.8 & & 10 & 8.3 \\
Antibiotics & 3 & 2.5 & & 3 & 2.5 \\
Vitamines & 5 & 4.1 & & 3 & 2.5 \\
Vaccines & 2 & 1.7 & & 2 & 1.7 \\
Antiemetics & 1 & 0.8 & & 1 & 0.8 \\
Sedatives & 1 & 0.8 & & 2 & 1.7 \\
Other drugs & 6 & 5.0 & & 8 & 6.6 \\
Total cases & 35 & 28.9 & & 37 & 30.6 \\
\hline Irradiation & 3 & 2.5 & & 4 & 3.3 \\
$\quad$ Chest & 1 & 0.8 & & 3 & 2.5 \\
Abdominal & 2 & 1.7 & & 0 & 0.0 \\
Neck & 0 & 0.0 & & 1 & 0.8 \\
\hline
\end{tabular}

No. of cases examined $=121$ in each group.

\section{Maternal exposure to drugs and ionizing radiation}

As shown in Table 16, there was no difference in the frequency of drug consumption and irradiation between the case mothers and the control mothers. Although the former involved more cases who ingested progestagens during pregnancy, these hormones had been given the women as a treatment of threatened abortion and therefore may not be causative. The history of abdominal X-ray exposure was reported by two mothers in the study group, but the number is too small to give some idea.

\section{Maternal smoking and alcohol consumption}

The frequency of smokers and alcohol consumers among the case mothers did 
Table 17. Smoking habit of the mothers in the study group and in the control group (paritymatched).

\begin{tabular}{cccccc}
\hline \multirow{2}{*}{ Smoking } & \multicolumn{2}{c}{ Mothers of polydactyls } & & \multicolumn{2}{c}{ Controls } \\
\cline { 2 - 3 } \cline { 5 - 6 } & No. & $\%$ & & No. & $\%$ \\
\hline$(+)$ & 8 & 6.6 & & 14 & 11.6 \\
$(-)$ & 86 & 71.1 & & 85 & 70.2 \\
Unknown & 27 & 22.3 & & 22 & 18.2 \\
\hline Total & 121 & 100.0 & & 121 & 100.0 \\
\hline
\end{tabular}

Table 18. Drinking habit of the mothers in the study group and in the control group (paritymatched).

\begin{tabular}{cccccc}
\hline \multirow{2}{*}{ Alcohol } & \multicolumn{2}{c}{ Mothers of polydactyls } & & \multicolumn{2}{c}{ Controls } \\
\cline { 6 - 7 } \cline { 5 - 6 } & No. & $\%$ & & No. & $\%$ \\
\hline$(+)$ & 13 & 10.7 & & 9 & 7.4 \\
$(-)$ & 32 & 26.4 & & 33 & 27.3 \\
Unknown & 76 & 62.6 & & 79 & 65.3 \\
\hline Total & 121 & 100.0 & 121 & 100.0 \\
\hline
\end{tabular}

not differ significantly from the respective values among the control mothers (Tables 17 and 18$)$.

\section{Family history and parental consanguinity}

Information on the family was obtained for only 67 cases. Only two of these $(1.7 \%$ ) had a family member with a congenital malformation; one had a sib with VSD and the other had a sib with atresia of the external acoustic meatus. The remaining 65 mothers did not recall any developmental abnormalities (including polydactyly) in their close relatives. Among the 67 parity-matched controls for which familial information was available, there were three cases which had another family member with congenital malformations; one of them had a relative with polydactyly.

None of the mothers in the study group admitted consanguinity between the spouses, whereas there was one $(0.8 \%)$ cousin marriage in the control group. Thus no indication of elevated parental consanguinity was revealed in this series of polydactylous embryos.

\section{DISCUSSION}

The examination of the present series revealed that polydactyly in Japanese embryos is predominantly preaxial. Perhaps this is an important feature of Japanese polydactyly, because in Negro and white populations, postaxial type is far 
Table 19. Preaxial/postaxial and unilateral/bilateral ratios of polydactyly in several racial groups.

\begin{tabular}{|c|c|c|c|c|c|c|}
\hline \multirow[b]{2}{*}{ Race } & \multirow[b]{2}{*}{$\begin{array}{l}\text { Incidence of } \\
\text { polydactyly } \\
\qquad \%)\end{array}$} & \multirow[b]{2}{*}{$\begin{array}{l}\text { No. of } \\
\text { cases } \\
\text { examined }\end{array}$} & \multicolumn{3}{|c|}{ Ratio } & \multirow[b]{2}{*}{ Authors } \\
\hline & & & $\begin{array}{l}\text { Preaxial : P } \\
(\quad) \text { : Unila } \\
\text { bilater }\end{array}$ & $\begin{array}{l}\text { ostaxial } \\
\text { teral vs. I } \\
\text { ral }\end{array}$ & Unilateral : Bilatera & \\
\hline \multicolumn{7}{|l|}{ Embryo } \\
\hline Japanese & 0.35 & 129 & $\begin{array}{c}73: \\
(70: 30)\end{array}$ & $\begin{array}{l}27 \\
(55: 45)\end{array}$ & $64: 36$ & Present study \\
\hline \multicolumn{7}{|l|}{ Newborn } \\
\hline $\begin{array}{l}\text { Chinese } \\
\text { (Hong Kong) }\end{array}$ & 0.06 & 15 & 60 & 40 & - & $\begin{array}{l}\text { Stevenson et al. } \\
\text { (1966) }\end{array}$ \\
\hline Latin American* & 0.10 & 188 & $\begin{array}{c}18: \\
(77: 23)\end{array}$ & $\begin{array}{l}82 \\
(58: 42)\end{array}$ & $62: 38$ & $\begin{array}{l}\text { Castilla et al. } \\
\text { (1973) }\end{array}$ \\
\hline American white & 0.08 & 32 & $7:$ & 93 & $(63: 37)^{* *}$ & \multirow{2}{*}{$\begin{array}{l}\text { Woolf and } \\
\text { Myriantho- } \\
\text { poulos (1973) }\end{array}$} \\
\hline American Negro & 1.2 & 344 & 1 & 99 & $(39: 61)^{* *}$ & \\
\hline
\end{tabular}

*From Urguay, Chile and Argentina. Ethnic groups involved were: Latin Europeans, non-Latin Europeans, Jews, natives, Arabians, Negroes, Orientals and others.

**For pedunculated postminimi only.

more frequently encountered than preaxial one (Table 19). Especially in Negro populations where the frequency of polydactyly is about ten times higher than that of the other ethnic groups, postaxial polydactyly occurs at an incidence rate of 13.5 per 1,000 against 0.08 per 1,000 for preaxial polydactyly (Woolf and Myrianthopoulos, 1973). Such a racial difference possibly reflects the difference in genetic constitutions between different racial groups. Referring to Table 19, the ratio unilateral to bilateral affection for preaxial or postaxial polydactyly appears almost invariant in the Japanese as well as in Latin American people (Castilla et al., 1973), though the relative frequencies of preaxial and postaxial polydactyly are almost inverse between the two populations. This suggests that each type of polydactyly, i.e., preaxial or postaxial, is etiologically alike in any racial group even if the relative frequencies are quite different.

In veiw of the known familial tendencies of postaxial polydactyly, the lack of the family histories of the anomaly in the present series was striking. In addition, none of the parents were found to be consanguineous. Hereditary cases, if any, might have been overlooked, or the mothers might have concealed the fact or they might have not noticed the presence of similar anomalies in their relatives because the deformities had been surgically removed. However, these cannot be the case in many of the instances. It can be pointed out that our system may not be highly effective for such data collection because the mothers were interviewed only by the obstetricians. Nevertheless one of the relatives of the 67 normal controls was found to have the same digital anomaly, suggesting that more than a few of the familial cases of polydactyly could not be overlooked if present. 
The apparent absence or extremely low frequency of affected relatives in our series, however, is consistent with the result obtained by Neel (1958) who examined the Japanese infant cases. According to Handforth (1950), among 14 Chinese prisoners with polydactyly (13 cases were preaxial and one was postaxial), there was only one who had a family history of supernumerary digits. The infrequent familial occurrence of polydactyly in Orientals is perhaps due to the fact that in this racial group, the proportion of preaxial polydactyly is much larger than in other groups. Therefore, in Orientals including Japanese, at least dominant inheritance is not a major component as causes of polydactyly and complex genetic mechanisms or unknown exogenous factors may be responsible for the majority of the cases.

Although polydactyly was shown to occur randomly through time, a bulk of the cases was noted in the years 1971 and 1972. Tanimura (1975) examined the variation in annual incidence of preaxial polydactyly of the hand among undamaged embryos from the same collection as ours, and demonstrated that the anomaly increased especially in 1971, being significant as compared with the preceding years. The significant increase in the incidence of preaxial polydactyly was also shown by the present study. Although the cause of the cluster in 1971 and 1972 is not clear, it seems that some unknown extraneous factors, most probably some kind of ascertainment bias, were at work temporarily, because postaxial and bilateral polydactyly for which the role of genetic component is known to be great also increased in those years and the incidence declined in 1973 and 1974 to around the mean level. It is noted that among the affected cases, the proportion of the embryos at stages 16 and 17 in which diagnosis of polydactyly is not always easy increased in 1971 and $1972(17 / 39 ; 43.6 \%)$ as compared with the preceding years $(26 / 80 ; 32.5 \%)$, but this fact alone does not explain the cluster in those years, and perhaps changing diagnostic criteria on the side of the investigators may be another cause.

In the present series, maternal parity was shown to have no effect upon the causation of polydactyly. Our data disclosed no evidence of parental age effect. As described earlier, polydactyly is known to present in patients with such chromosomal aberrations as trisomy 13 (Teller and Pfeiffer, 1964; Warkany et al., 1966; Taylor, 1968; Dallapiccola and Pistocchi, 1972), trisomy 18 (Goodman, 1963; Schinzel and Schmid, 1971), trisomy 21 (Hanhart, 1960; Fabia and Drolette, 1970; Dignan, 1973), and 13q + (Pfeiffer and Santelmann, 1977). Above all, polydactyly is a typical feature of trisomy 13; partial or complete duplication of the digit is seen in about $80 \%$ of the cases (Pfeiffer and Santelmann, 1977). In addition, it is known that trisomies 13, 18 and 21 occur in close relation with advancing maternal age (Lenz and Lenz, 1968; Lenz, 1970). Consequently, if our series had contained an appreciable number of these trisomics, a proportionate rise in maternal age should be detected. Supposing that the relative risk of trisomies 13 and 18 increases with advancing maternal age in a fashion similar to that of trisomy 21 and that all of the present cases were of trisomies 13,18 or 21 , it is expected that the mean maternal age should be about 35 years. However, the observed mean age of the case 
mothers was 30.1 which was higher than the expected value by only 0.35 year. Thus the chromosomal aberrations for which the risk increases with advancing maternal age may, if any, not constitute a major part as causes of polydactyly in human embryos. However, the role of chromosomal aberrations in the etiology of polydactyly should be examined in future by cytogenetic studies of polydactylous embryos.

Except the history of pathological genital bleeding, our results disclosed no association between polydactyly and maternal medical history, including irregular menstruation, and smoking and drinking habit. The commonly used drugs as listed in Table 16 had no indication to cause polydactyly in man. One of the suggestive findings disclosed by the present study was that the mothers of the polydactylous embryos had more frequently miscarriages prior to the index pregnancy than the control mothers, though the difference was statistically not significant. This finding supports the view that some kind of maternal predisposition, genetic and/or environmental, may be responsible for this malformation. Formally, such predisposition may involve recessive mutant genes, polygenes, or chronic maternal illness or intoxication. In our data, however, there was no indication of increased rate of parental consanguinity, indicating that most of the present cases were attributed to the causes other than rare autosomal recessive genes. No suggestion was given with respect to the possible role of maternal chronic diseases or intoxication. Although none of our cases were found to be familial, it is conceivable that the cases involving bilateral hands or feet and at least those involving all four limbs may have more or less genetic basis. Further detailed studies of the family members are required.

Acknowledgments The authors are indebted to Professor H. Nishimura and his associates of the Department of Anatomy and Human Embryo Center for Teratological Studies, Faculty of Medicine, Kyoto University. The help of the several hundred obstetricians who provided the embryonic specimens is also acknowledged. This study, contribution no. 1190 from the National Institute of Genetics, was supported by grants from the Ministry of Education, Science and Culture and the Ministry of Health and Welfare of Japan.

\section{REFERENCES}

Altemus, L. A. and Ferguson, A. D. 1965. Comparative incidence of birth defects in Negro and white children. Pediatrics 36: 56-61.

Castilla, E., Paz, J., Mutchinick, O., Muñoz, E., Giorgiutti, E., and Gelman, Z. 1973. Polydactyly: A genetic study in South America. Am. J. Human Genet. 25: 405-412.

Dallapiccola, B. and Pistochi, G. F. 1972. Malformatione scheletriche da observazione cromosomiche. Studio clinico radiolog. Minerva Med. (Torino) 63: 5049-5208.

Dignan, P. S. J. 1973. Polydactyly in Down's syndrome. Am. J. Ment. Defic. 77: 486-491.

Fabia, J. and Drolette, M. 1970. Malformations and leukemia in children with Down's syndrome. Pediatrics 45: 60-70.

Frazier, T. M. 1960. A note on race-specific congenital malformation rates. Am. J. Obstet. Gynecol. 80: 184-185. 
Goodman, R. M. 1963. Medical genetics and practicing physician. Gen. Pract. 27: 108-118. Handforth, J. R. 1950. Polydactylism of hand in southern Chinese. Anat. Rec. 106: 119-125.

Hanhart, E. 1960. 800 Fälle von Mongoloidismus in konstitutioneller Betrachtung. Arch. KlausStift Vererb. Forsch, 35: 7-312.

Lenz, W. 1970. Birth defects-genetic aspects. In: Congenital Malformations (F. C. Fraser and V. A. McKusick, eds.), Excerpra Medica International Congress Series, Excerpta Medica, Amsterdam and New York, Vol. 204, pp. 402-406.

Lenz, W. and Lenz, F. 1968. Grundlinien der Humangenetik. Zu Definition, Terminologie und Methoden. In: Humangenetik (P. E. Becker, ed.), Georg Thieme Verlag, Stuttgart, Bd. I/1, pp. 1-76.

Matsunaga, E. and Shiota, K. 1977. Holoprosencephaly in human embryos: Epidemiologic studies of 150 cases. Teratology 16: 261-272.

McKusick, V. A. 1975. Mendelian Inheritance in Man. Catalogs of Autosomal Dominant, Autosomal Recessive, and X-linked Phenotypes. 4th ed. Johns Hopkins University Press, Baltimore, pp. 268-270.

Mitani, S. 1954. Malformations of the newborn infants. J. Jap. Obstet. Gynecol. Soc. 1: 301-315.

Neel, J. V. 1958. A study of major congenital defects in Japanese infants. Am. J. Human Genet. 10: $398-445$.

Nishimura, H. 1970. Incidence of malformations in abortions. In: Congenital Malformations (F. C. Fraser and V. A. McKusick, eds.), Excerpta Medica International Congress Series, Excerpta Medica, Amsterdam and New York, Vol. 204, pp. 275-283.

Nishimura, H. and Okamoto, N. 1976. Sequential Atlas of Human Congenital Malformations. Observations of Embryos, Fetuses and Newborns. Igaku Shoin, Tokyo, pp. 242-249.

Nishimura, H., Takano, K., Tanimura, T., and Yasuda, M. 1968. Normal and abnormal develcpment of human embryos: First report of the analysis of 1,231 intact embryos. Teratology 1: 281-290.

Ohkura, K. 1956. Clinical genetics of polydactylism. Jap. J. Human Genet. 1: 11-23.

Pfeiffer, R. A. and Santelmann, R. 1977. Limb anomalies in chromosomal aberrations. Birth Defects Orig. Art. Ser. 13(1): 319-337.

Schinzel, A. and Schmid, W. 1971. Trisomie 18. Helv. Paediat. Acta 26: 673-685.

Simpkiss, M. and Lowe, A. 1961. Congenital abnormalities in the African newborn. Arch. Dis. Childh. 36: 404-406.

Smith, D. W. 1970. Recognizable Patterns of Human Malformation. Genetic, Embryologic, and Clinical Aspects. W. B. Saunders, Philadelphia.

Stevenson, A. C., Johnston, H. A., Stewart, M. I. P., and Golding, D. R. 1966. Congenital malformations. A report of a study of series of consecutive births in 24 centres. Bull. W.H.O. 34 (suppl.): 1-127.

Tanimura, T. 1975. Invited discussion: The use of induced abortuses for monitoring. In: Methods for Detection of Environmental Agents that produce Congenital Defects (T. H. Shepard, J. R. Miller and M. Marois, eds.), North-Holland Publishing Co., Amsterdam, pp. 197-201.

Taylor, A. I. 1968. Autosomal trisomy syndromes. A detailed study of 27 cases of Edwards' syndrome and 27 cases of Patau's syndrome. J. Med. Genet. 5: 227-252.

Teller, W. and Pfeiffer, R. A. 1964. Die Trisomie D; (13-15) als Ursache multipler Abartungen. Z. Kinderheilkd. 89: 36-48.

Temtany, S. and McKusick, V. A. 1969. Synopsis of hand malformations with particular emphasis

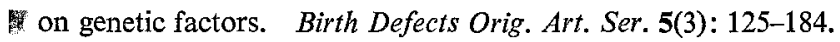

Warkany, J. 1971. Congenital Malformations. Notes and Comments. Year Book Medical Publishers, Chicago, pp. 978-984.

Warkany, J., Passarge, E., and Smith, L. B. 1966. Congenital malformations in autosomal trisomy 
syndromes. Am. J. Dis. Child. 112: 502-517.

Woolf, C. M. and Myrianthopoulos, N. C. 1973. Polydactyly in American Negroes and whites. Am. J. Human Genet. 25: 397-404.

Woolf, C. M. and Woolf, R. M. 1970. A genetic study of polydactyly in Utah. Am. J. Human Genet. 22: 75-88. 